\title{
LEGISLACIÓN Y TRATAMIENTO DE LOS MENORES QUE COMETEN DELITOS ANTES DE LOS 14 AÑOS
}

\author{
LEGISLATION AND LEGAL TREATMENT OF YOUNG \\ OFFENDERS WHO COMMIT CRIMES UNDER THE AGE OF 14
}

\author{
DAVID SIESTO MARTÍN \\ Doctorando área de Derecho Penal \\ dsiestom@gmail.com \\ Universidad de Málaga
}

\begin{abstract}
Resumen:
La promulgación de la LO 5/2000 hace ya casi dos décadas, supuso un importante reto para las comunidades autónomas. No en vano, éstas tuvieron que asumir la competencia de la respuesta a los delitos cometidos de los infractores de edad inferior a 14 años. En el seno de cada comunidad fueron los servicios de Protección de la Infancia los encargados de esta labor, teniendo que reinventarse ante la nueva exigencia. Sin embargo, a día de hoy, persisten todavía dudas sobre la idoneidad y la capacidad de este sistema para hacer frente a semejante desafío.

En este trabajo pretendemos poner de relieve algunas de las intervenciones operadas por ciertas entidades del panorama nacional que trabajan con los delincuentes menores de14 años, haciendo un especial seguimiento a la situación actual de la comunidad autónoma de Andalucía y en particular, a la provincia de Málaga. Gracias a las aportaciones de expertos en el ámbito social y jurídico trataremos de arrojar algo de luz a esta realidad no tan conocida por la sociedad.
\end{abstract}

Palabras clave: menores infractores, minoría de edad penal, delincuencia juvenil, justicia juvenil, sistema de protección de la infancia.

\footnotetext{
Abstract: challenge.

REJIE Nueva época: Revista Jurídica de Investigación e Innovación Educativa

Núm.20, Junio 2019, pp. 133-155

[En línea] http://www.revistas.uma.es/index.php/rejie

Recibido: marzo 2019

Aceptado: mayo 2019
}

The promulgation of the Law LO 5/2000 since almost two decades ago, represented an important challenge for the autonomous communities. Not in vain, these had to assume the competence of responding to crimes committed of those offenders under the age of 14 years. The Child Protection Services were responsible for this work within each community, having to reinvent itself in the face of new demands. However, to this day, there are still doubts about the suitability and capacity of this system to face such a

On the basis of this work, we intend to highlight some of the interventions operated by certain entities on the national scene who work with offenders under the age of 14 , making a special follow-up to the current situation of the autonomous community of Andalusia and in particular, the province from Malaga. Thanks to the contributions of 
experts in the social and legal field we will try to shed some light on this reality which is not so well known by society.

Keywords: young offenders, minors and criminal liability, juvenile delinquency, youth crime, juvenile justice, child protection system crime, juvenile justice, child protection system.

Sumario: 1. Introducción. 2. Objetivos. 3. Hipótesis. 4. Metodología. 5. Marco legal a nivel nacional y en la comunidad autónoma de Andalucía. 6. Experiencias concretas de varias provincias españolas. 7. El tratamiento institucional de los menores que cometen delitos antes de los 14 años en Málaga. 7.1. Antecedentes. 7.2. Recorrido vital de un menor de 14 años a través de las distintas instituciones cuando comete un delito en Málaga. 8. Conclusiones. Bibliografía.

\section{Introducción.}

La preocupación e interés inusitados por la delincuencia juvenil se encuentran arraigados en lo más profundo de las sociedades, conformándose como imperecederos al paso del tiempo ${ }^{1}$. No es de extrañar si tenemos en cuenta la elevada atención que recibe la delincuencia en su versión adulta. Sin embargo, cuanto menor es la edad del delincuente más miradas atrae, tornando el interés casi en estupor.

Siguiendo el planteamiento del párrafo anterior, los delitos cometidos por menores de 14 años ocupan gran parte de las tribulaciones de los ciudadanos en lo que a delincuencia se refiere. La extrema juventud de los implicados contribuye a partes iguales con una desorbitada y desenfocada atención mediática, a generar una percepción cuanto menos imprecisa de la realidad delincuencial atinente a estos menores ${ }^{2}$.

Los ingredientes presentados predisponen al debate sobre la supuesta "mano blanda" hacia estos delincuentes ${ }^{3}$, y hace ganar enteros a la posibilidad de reducir la edad penal mínima de exigencia de responsabilidad para dar una respuesta "acorde" a la magnitud de este fenómeno delictivo ${ }^{4}$.

1 PACHECO GALLARDO, M., “Criminología Juvenil”, 2019, Noticias Jurídicas. [En línea] http://noticias.juridicas.com/conocimiento/articulos-doctrinales/4333-criminologia- juvenil-/.

2 SOTO NAVARRO, S. 2005, "La influencia de los medios en la percepción social de la delincuencia", Revista Electrónica de Ciencia Penal y Criminología, nº46: p. 3 . [En línea] http://criminet.ugr.es/recpc/07/recpc07-09.pdf

${ }^{3}$ La forma más común de los ciudadanos de percibir la delincuencia juvenil es con una fuente constante de peligro y por ende, la sociedad debe reaccionar vehementemente ante los ataques de los jóvenes. CABEZAS SALMERÓN, J. 2012, "Protegernos de los jóvenes", Revista Crítica Penal y Poder, n 2, p: 190. [En línea] http://revistes.ub.edu/index.php/CriticaPenalPoder/article/view/2951/3214

${ }^{4}$ El eco de un descenso en la edad penal mínima no ha dejado de retumbar desde la gestación de la LO 5/2000, como así lo atestigua el proyecto de la el Proyecto de Ley Orgánica reguladora de la responsabilidad penal de los menores presentado por el Gobierno de España (BOCG. Congreso de los Diputados, serie A, núm. 144-1, de 03/11/1998) que pretendía bajar el umbral hasta los 13 años. Este debate permanece latente hasta que en determinados momentos se torna cruento como sucedió por ejemplo en 2009 con la supuesta violación de dos menores por un grupo dónde había menores de 14 años. [En línea] http://www.elperiodicoextremadura.com/noticias/sociedad/edad-penal-14-anos-divide-juristaspoliticos_455842.html 
A nivel legal no existe discusión en la medida que la promulgación de la LO 5/2000 reguladora de la Responsabilidad Penal de los Menores (en adelante LO 5/2000) estipuló en su articulado la irresponsabilidad penal de los menores de 14 años, haciendo competente de su tratamiento a la Ley Orgánica 1/1996, de 15 de enero, de Protección Jurídica del Menor, de modificación parcial del Código Civil y de la Ley de Enjuiciamiento Civil( en adelante LO 1/1996), y al propio Código Civil (en adelante $\mathrm{CC})$.

En medio de la controversia circundante a cuál debe de ser la estrategia político criminal a seguir con esta población infractora, se encuentra un grupo de profesionales de diferentes campos que se encarga de la intervención con estos menores, provistos de las herramientas proporcionadas por este Sistema de Protección de la Infancia y la Adolescencia repleto de ambages e imprecisiones que impiden en gran medida un desarrollo adecuado de sus funciones.

La loable y decidida decisión de mantener al margen del Sistema de Justicia Juvenil a los menores de 14 años, ha desembocado en un compendio de dispares estrategias de intervención a lo largo y ancho del país merced a la descentralización del Estado en materia de Protección de Menores.

Ante tal fotografía surge la duda de si el ansiado objetivo de formar una barrera preventiva eficiente para evitar el futuro contacto de estos menores con las instancias judiciales ha llegado a un grado de consecución óptimo, o si por el contrario, nos hemos embarcado en un viaje a un tiempo pretérito cercano al paradigma tutelar ${ }^{5}$.

Sea como fuere urge analizar pormenorizadamente las respuestas institucionales ofrecidas a los menores de 14 años que han cometido delitos antes de la edad penal. Y no es baladí esta cuestión porque tan importante es la meta como la forma de llegar a ella. Efectivamente, no se trata aquí de ceñirse al límite de edad establecido por imperativo legal apartando a estos menores sin ningún orden ni concierto, alejándolos momentáneamente de la crudeza de la justicia penal hasta que el simple paso del tiempo los introduzca definitivamente en sus entrañas ${ }^{6}$. Esta actitud negligente desencadenaría en un error mayúsculo con dos graves consecuencias: la primera, la revitalización del sentimiento de impunidad del infractor fruto de la incoherencia de un sistema perfilado

\footnotetext{
${ }^{5}$ La ausencia de control judicial puede conllevar ciertas prácticas similares a las empleadas por el antiguo sistema tutelar de menores; propiciando que en aras del interés superior del menor pudieran aplicarse medidas de igual o superior lesividad a las propias del Sistema Juvenil de Justicia CABEZAS SALMERÓN, J. 2011, "Superación del modelo anterior de Justicia Juvenil(tutelar) por el actual modelo de responsabilidad(de responsabilidad) ¿Se lo ha creído alguien?”, Revista Crítica Penal y Poder, $\mathrm{n}^{\circ}$ 1: $\mathrm{p}$. 171.

[En línea] revistes.ub.edu/index.php/CriticaPenalPoder/article/download/1991/2087

${ }^{6}$ El principal objetivo de la intervención temprana mediante el sistema de Protección es evitar la futura entrada en el Sistema de Justicia Juvenil. Algunos estudios indican la preocupante conexión entre ambas instituciones. LUZÓN GARCÍA, A. \& DOMÍNGUEZ ALONSO, J. 2014, "El menor infractor que comete su primer delito", Revista sobre la infancia y la adolescencia, no7: p. 55. [En línea] https://www.researchgate.net/publication/287415919_El_menor_infractor_que_comete su_primer_delito; CARRASCO, N.; GARCÍA, J.; \& ZALDÍVAR, F. 2014, "Estimación y caracterización de los antecedentes de protección de los menores infractores", Anuario de Psicología Jurídica, vol. 24, n¹: pp.31-35. [En línea] https://www.redalyc.org/articulo.oa?id=315031876004
} 
hacia la asunción de la responsabilidad de los hechos cometidos, que sin embargo exonera de toda responsabilidad al mismo infractor cuando comete un delito ${ }^{7}$; la segunda acarrearía un desencanto generalizado traducido en una desconfianza en el Sistema de Protección de la Infancia y Adolescencia, alimentando la vorágine punitivista de gran parte de la sociedad por un $\mathrm{lado}^{8}$, y la impotencia conformista de los profesionales involucrados por otro.

Ahora bien, puestas las piezas sobre el tablero y destacados los nada desdeñables intereses en juego, se hace necesaria la articulación de una réplica adecuada y educativa a estos menores que se erija como divergente a la judicial, empero a su vez distanciada del influjo protector ${ }^{9}$.

Titánica tarea se antoja desentrañar los entresijos del funcionamiento de la intervención con los delincuentes menores de 14 años. La dificultad reside en el aura de oscurantismo imperante alrededor de las competencias, funciones y objetivos de todos los elementos integrados dentro del organigrama ideado para dicha actuación.

El legislador intentó paliar la opacidad de ciertos preceptos y conceptos presentes en la legislación encargada del sistema de protección de la infancia y la adolescencia, reformando profundamente la LO1/1996 a través de la Ley Orgánica 8/2015, de 22 de julio, de modificación del sistema de protección de la infancia y adolescencia, BOE de 23 de julio de 2015, en relación a los preceptos que tienen carácter orgánico (en adelante LO 8/2015), y la Ley 26/2015, de 28 de julio, de modificación del sistema de protección de la infancia y adolescencia, BOE de 29 de julio de 2015 respecto a los sometidos a la ley ordinaria (en adelante Ley 26/2015).

Como veremos en los epígrafes siguientes, para la temática protagonista de este trabajo, la mencionada reforma no ha traído cambios significativos aunque si ha mejorado ciertos aspectos definitorios. Las experiencias diarias de los profesionales provenientes de las distintas áreas serán las que arrojen luz sobre esta problemática, constituyéndose en verdaderos protagonistas de la evolución del tratamiento de este colectivo delincuencial.

\footnotetext{
7 BERNUZ, M. J.; FERNÁNDEZ, E. \& PÉREZ, F. 2007, "Menores de 14 años que cometen delitos", Boletín Criminológico sección de Málaga IAIC, $\mathrm{n}^{\circ}$ 97: p.1. [En línea] http://www.boletincriminologico.uma.es/boletines/97.pdf

${ }^{8}$ El prisma difuso cosechado a medias por los medios de comunicación y los entes políticos se corona como el elemento catalizador de la mirada de la sociedad. La derivación natural es una visión sesgada y perversa de la delincuencia juvenil en general y particularmente diabólica de la gravedad de la misma. El dictamen del Comité Económico y social Europeo sobre $<<$ La prevención de la delincuencia juvenil y el papel de la justicia del menor en la Unión Europea〉> aprobado en el $425^{\circ}$ Pleno de los días 15 y 16 de marzo de 2006, recalca como no puede pasar inadvertido lo erróneo de esta realidad ficcionada porque repercute negativamente en la consideración del menor delincuente. Ante la desinformación evidente, la única opción es una mayor trasparencia para que como dice el art 1.5, ["contribuyan a desdramatizar y situar en sus justos términos la percepción exageradamente negativa"]. [En línea] https://eur-

lex.europa.eu/LexUriServ/LexUriServ.do?uri=OJ:C:2006:110:0075:0082:ES:PDF

${ }^{9}$ BERNUZ, M. J.; FERNÁNDEZ, E. \& PÉREZ, F. 2006, "El tratamiento institucional de los menores que cometen delitos antes de los 14 años", Revista Española de Investigación Criminológica, $\mathrm{n}^{\circ} 4$. artículo 5: p. 5.
} 


\section{Objetivos.}

Después de más de tres lustros de rodaje desde la promulgación de la LO 5/2000, las instituciones de Protección de la infancia han ido perfeccionando la actuación con los menores delincuentes de 14 años. Si bien el sistema de protección partía con planteamientos típicos de desprotección y abandono, poco a poco ha mejorado paulatinamente sus prestaciones, acondicionándose a las exigencias de respuesta para con una población claramente fuera del perfil base al que estaban acostumbrados a tratar. Esta adaptación progresiva se ha llevado a cabo desde dos ejes bien diferenciados pero íntimamente ligados. De una parte, el legislador tanto nacional como autonómico no ha permanecido impasible ante la evolución del fenómeno y ha centrado sus esfuerzos en intentar dotar de unas herramientas legales más útiles para la intervención. De otra parte, los propios profesionales basándose en su labor con estos menores, han diseñado programas cada vez más adaptados a sus necesidades.

Por todo ello, con la información disponible en referencia a la legislación involucrada y a la actuación de los servicios de protección, los objetivos exploratorios propuestos son los siguientes:

1. Plasmar de forma clara qué legislaciones están presentes en el tratamiento de los menores delincuentes de 14 años a nivel nacional y a nivel de Andalucía.

2. Mostrar distintos tratamientos que reciben estos menores en España. El objetivo prioritario siempre será descubrir las mecánicas de respuesta instauradas en algunas provincias de diferentes comunidades.

3. Abordar pormenorizadamente los dos puntos anteriores focalizando la atención en la ciudad de Málaga.

\section{Hipótesis de investigación.}

Las hipótesis planteadas inicialmente como guía de trabajo servirían de punto de arranque de la investigación. Al abarcar tres realidades diferentes del Sistema de Protección (nacional, autonómica y local) convenimos apropiado destinar una hipótesis a verificar aspectos evolutivos de cada una de las dimensiones. En consonancia, a continuación se muestran las referidas hipótesis:

- Hipótesis a nivel nacional: Las reformas de 2015 de la LO 1/1996 no se han visto correspondidas con un marco legal más adaptado a la respuesta de los menores de 14 años que delinquen.

- Hipótesis a nivel autonómico: La cobertura de la Ley 1/1998, de 20 de abril, de los derechos y la atención al menor (en adelante LO 1/1998) derivará una actuación igualitaria en todas las provincias con estos menores.

- Hipótesis a nivel local: En Málaga no se ha implementado ningún programa de tratamiento específico destinado a este colectivo.

\section{Metodología.}

La investigación se asienta en dos secciones netamente diferenciadas y en consecuencia la técnica usada para obtener la información debe ajustarse a la naturaleza de la fuente. 
Esta razón nos llevó a plantear una metodología de carácter cualitativo divida en dos partes. Una primera enfocada en dibujar el armazón legal encargado de la intervención de menores de 14 años. Para ello, se hizo una revisión jurídica actualizada de la legislación competente en esta materia a nivel nacional y andaluz.

La segunda parte pretendía obtener información de primera mano de la realidad de las actuaciones llevadas a cabo con estos menores por los distintos operadores con los que mantienen contacto. Para su consecución, y con la pretensión de emular en la medida de lo posible el orden de intervención con estos menores, se realizaron entrevistas semiabiertas dentro de un proceso similar al empleado en muestreo por bola de nieve. De esta manera, cada entrevistado nos conducía a otro experto, hasta conseguir toda la información necesaria. Como no podía ser de otra forma, los expertos entrevistados pertenecen tanto al mundo jurídico como al mundo social, y comparten su día a día con este segmento de población de menores. Más concretamente, se hicieron un total de 12 entrevistas que tuvieron como protagonistas a miembros de la Fiscalía de Protección de Menores y profesionales de los Servicios de Protección de la Infancia y la Adolescencia de la ciudad de Málaga, así como trabajadores de organizaciones y asociaciones encargados de gestionar el tratamiento con los menores objeto de estudio en otras provincias.

Atendiendo a la diversidad formativa y a las diferencias notables del trabajo desempeñado por los entrevistados, se acuñaron una serie de preguntas destinadas a saber cuál era su actuación con el menor, la relación mantenida con otras instituciones involucradas, su opinión sobre la conveniencia de una creación de un equipo de tratamiento específico y su posicionamiento en torno a la posibilidad de bajar la edad de responsabilidad penal a menos de 14 años.

\section{Marco legal a nivel nacional y en la C.A. de Andalucía.}

El camino procesal a recorrer por estos infractores, dista abismalmente al de cualquiera de las franjas de edad estructuradas para los individuos de superior recorrido vital. La reafirmación rotunda de este hecho comienza con la lectura del C.P., que de forma expresa deja fuera de su ámbito de actuación a los menores de 18 años, derivándolos a lo dispuesto en la LO $5 / 2000^{10}$.

La remisión directa a la LO 5/2000 no es más que una reubicación, puesto que la mencionada LO, especifica su incompetencia para con los menores de 14 años ${ }^{11}$. Con este nuevo desvío, se pone en liza la imposibilidad de una respuesta penal a este colectivo $^{12}$. La carencia de réplica penal no significa una ausencia total de reacción

\footnotetext{
${ }^{10}$ Vid art.19 C.P.

${ }^{11}$ El art. 3 LO 5/2000 dedica su título y contenido a explicar que a los delincuentes menores de 14 años "no se les exigirá responsabilidad con arreglo a esta ley". De igual forma, también recoge las disposiciones pertinentes que se centraran en su tratamiento.

12 Debemos tener presente que la despenalización de un comportamiento no significa la negación de responsabilidad del autor, solamente se está evitando la forma más extrema de responsabilidad. GARCÍA PÉREZ, O. 1999, "Los actuales principios del derecho penal juvenil: un análisis crítico", Revista de derecho penal y criminología: pp. 71 y ss. Más bien, la negación de la reacción penal forma parte de la estrategia designada por la política criminal juvenil. Esta preferencia obedece a capitales razones: la confianza en la respuesta del sistema de protección, la tasa relativamente baja de esta delincuencia, la poca entidad del delito cometido por los menores de 14 y la exigencia de la Convención de los derechos del Niño. BERNUZ et al., "El tratamiento...", op. cit.: p. 2
} 
frente a estos delincuentes, dado que la inacción acarrearía importantes consecuencias negativas con los propios menores implicados ${ }^{13}$.

Descartada la maquinaria penal, el art.3 de la LO 5/2000, redirecciona a los infractores menores de esta barrera etaria a lo dispuesto en el Código Civil (en adelante CC) y en la LO 1/1996. En definitiva, existe la firme voluntad de evitar la vía penal, consignando a estos menores al denominado sistema de protección a la infancia y a la adolescencia. La definición pertinente a este sistema mencionado en el renglón anterior, respondería a: "conjunto de actuaciones que, en el marco del sistema público de servicios sociales, tiene como finalidad prevenir, detectar y corregir las situaciones de riesgo y desamparo, mediante la integración del menor en grupos naturales de convivencia, en condiciones básicas suficientes que posibiliten su participación en la vida familiar, económica, social y cultural y su desarrollo integral como persona"14.

Amén de otras disposiciones, el armazón jurídico del sistema de protección se encuentra representado por la LO 1/1996 ${ }^{15}$. La LO 1/1996 por tanto, se erige como la ley base a nivel nacional en la materia de protección de la infancia y la adolescencia. Ahora bien, debido a lo dispuesto por la Constitución Española (en adelante CE), en relación a las competencias asignadas a las $\mathrm{CCAA}^{16}$, las disposiciones generadas desde las CC.AA van a tener una relevancia preponderante sobre protección y atención al menor, actuando la legislación estatal como límite en virtud al principio de unidad ${ }^{17}$.

Este periplo jurídico remarca la capacitación de las instituciones de protección de la Infancia y la Adolescencia como garantes últimos de la intervención ${ }^{18}$. Entrando más en detalle, el funcionamiento del sistema de protección contempla fundamentalmente dos situaciones: de riesgo y de desamparo.

El establecimiento de una conceptualización precisa de ambos términos representa uno de los mayores retos del sistema de protección de la Infancia y la Adolescencia. En su redacción primigenia, la situación de riesgo no era detallada por la LO 1/1996. El art. 17 se limitaba a describir situación de riesgo como "de cualquier índole que perjudiquen el desarrollo personal o social del menor, que no requieran la asunción de la tutela por ministerio de la Ley ${ }^{19}$. Esta definición pecaba de una inconsistencia manifiesta,

\footnotetext{
${ }^{13}$ El perjuicio ocasionado por el sentimiento de impunidad reforzaría la actividad delictiva. En esta línea BERNUZ et al. coinciden en resaltar el extraordinario perjuicio de la declaración de impunidad y la ausencia de respuesta, Ibid.: p. 5. Igualmente, la FGE en su memoria del año 2008 ya expresó su preocupación por la sensación de impunidad que pudieran percibir los menores en caso de no existir respuesta conveniente, pp. 831-833.

En esta palabras se expresa el Art. 45 la ley 12/2001. De forma similar, Sáez Tejerina, M. L. 2004, "La protección de la infancia en España y en las comunidades autónomas". Cuartas jornadas sobre Infancia, Redes de formación e investigación para la promoción de los derechos de la Infancia, sesión 5: p.2. [En línea] https://www.uam.mx/cdi/pdf/eventos/jornadas_4/proteccion.pdf

${ }^{14}$ En esta palabras se expresa el Art. 45 la ley 12/2001. De forma similar, SÁEZ TEJERINA, M. L. 2004, "La protección de la infancia en España y en las comunidades autónomas". Cuartas jornadas sobre Infancia, Redes de formación e investigación para la promoción de los derechos de la Infancia, sesión 5: p.2. [En línea] https://www.uam.mx/cdi/pdf/eventos/jornadas_4/proteccion.pdf

${ }^{15}$ Esta intención se corrobora con lectura del apartado 2 de la EM de la LO 1/1996.

${ }^{16}$ Acerca de las competencias de las CCAA respecto a la asistencia social, véase el art.148.1.20 CE.

17 Vid. ALEMÁN BRACHO, C. 2014, "Políticas públicas y marco de protección jurídica del menor en España”, UNED. Revista Derecho Político, vol. 90: pp. 114-115.

18 Vid.Art.8.6 del Reglamento 1774/2004.

${ }^{19}$ Vid. Art. 17 LO 1/1996.
} 
haciéndose necesaria una versión definitoria mucho más específica para que no pareciera una suerte de cajón de sastre que albergara cualquier problemática en cuestión de protección de menores.

No mucha mejor suerte corrió la delimitación del concepto de desamparo en su primera versión dentro de la LO 1/1996. El art.18 LO 1/1996 lejos de identificar las situaciones de desamparo, dejaba al arbitrio de la entidad pública competente la consideración de situación de desamparo ${ }^{20}$.

En contraste con el demérito de no atesorar una definición concreta de las situaciones de riesgo y desamparo, LO 1/1996 supuso la diferenciación de ambas situaciones, al menos formalmente ${ }^{21}$. El vacío definitorio desembocó en una proliferación de versiones más o menos acertadas de las situaciones de riesgo y desamparo de génesis autonómica. El intento decidido en el seno de diferentes CCAA tenía el firme propósito de completar la deficiente redacción de la ley estatal, la LO 1/1996. Sin embargo, no fue hasta el advenimiento de las reformas de la LO 1/1996 en 2015 cuando verdaderamente concretó una descripción mucho más afinada tanto de la situación de riesgo como de la de desamparo.

El contenido de la reforma constó de dos leyes: la LO 8/2015, en relación a los preceptos que tienen carácter orgánico, y la Ley 26/2015, respecto a los sometidos a la ley ordinaria ${ }^{22}$. El reajuste legislativo conllevó cambios sustanciales en varias disposiciones aparte de los asociados a la LO 1/1996 ${ }^{23}$. Desgranando las abundantes novedades que trajo consigo esta ley, nos encontramos con cambios significativos en relación al objeto de este trabajo. En primer lugar, la concreción de las situaciones que dan pie al riesgo o al desamparo, y en segundo lugar, la inclusión de una importante novedad en el campo del acogimiento residencial, como son los centros de protección específica destinados a los menores con trastornos de conducta.

En alusión a la redacción de la situación de riesgo, la ley 26/2015 modificó el art. 17 de la LO 1/1996 quedando confeccionado como sigue: <<Se considerará situación de riesgo aquella en la que, a causa de circunstancias, carencias o conflictos familiares, sociales o educativos, el menor se vea perjudicado en su desarrollo personal, familiar, social o educativo, en su bienestar o en sus derechos de forma que, sin alcanzar la entidad, intensidad o persistencia que fundamentarían su declaración de situación de desamparo y la asunción de la tutela por ministerio de la ley, sea precisa la intervención de la administración pública competente, para eliminar, reducir o compensar las dificultades o inadaptación que le afectan y evitar su desamparo y exclusión social, sin tener que ser separado de su entorno familiar $>>$.

\footnotetext{
${ }^{20}$ La situación de desamparo se encontraba "desamparada" sin una descripción más concreta de los casos asimilables por esta figura. Vid art. 18. LO 1/1996 en su redacción original.

${ }^{21}$ La distinción entre riesgo y desamparo dentro de las situaciones de desprotección social del menor posee una relevancia práctica vital porque permite graduar la intervención de la Entidad Pública. Véase BENAVENTE MOREDA, P. 2011, "Riesgo, Desamparo y Menores .Actuación de la Administración e intereses en juego", AFDUAM, vol.15: p. 22.

${ }^{22}$ La LO 8/2015 adquirió el rango de ley orgánica porque afectaba a derechos fundamentales y libertades públicas. Así por ejemplo, regula cuestiones como el internamiento en centros en caso de trastorno de conducta, o la entrada en domicilio para la ejecución de medidas de protección

23 Consultar al respecto MORENO-TORRES SÁNCHEZ, J. 2015, "Modificación del Sistema de Protección a la Infancia y a la Adolescencia”, Save the Children: p. 10.
} 
El mencionado art. 17 desarrolla de forma integral la situación de riesgo y su procedimiento. Cuando la administración considere que la situación de desprotección no alcanza la entidad suficiente como para separar al menor de su enclave familiar efectuará una intervención preventiva encaminada a reducir los indicadores de riesgo, a la vez que se promueven los factores de protección del entorno del menor.

La declaración de la situación de riesgo acarreará inexorablemente la elaboración de un proyecto de intervención social y educativo familiar que deberá recoger los objetivos, actuaciones, recursos y previsión de plazos, promoviendo los factores de protección del menor y manteniendo a éste en su medio familiar. La intervención por parte de la administración pública competente podrá ser llevada a cabo por dos vías diferenciadas ${ }^{24}$ :

El elemento clave de la resolución es la inclusión de unas directrices de actuación de cómo deben proceder para corregir la situación de riesgo y evitar así una futura declaración de desamparo.

Mientras tanto a lo largo de los 15 años primeros años del siglo XXI, las CC.AA fueron complementando la versión de la situación de riesgo estatal, incorporando ciertos matices a la descripción de las situaciones puntuales que posibilitaban declarar la situación de riesgo ${ }^{25}$. En el caso de Andalucía, la mejora no fue muy acusada, pero hubo un avance en la concreción, como se puede apreciar repasando el art.22 de la LO 1/1998:"Se consideran situaciones de riesgo aquellas en las que existan carencias o dificultades en la atención de las necesidades básicas que los menores precisan para su correcto desarrollo físico, psíquico y social, y que no requieran su separación del medio familiar".

Aludiendo a la problemática tratada en este trabajo, el hecho delictivo cometido por los menores circunscritos al segmento de edad protagonista podría asimilarse dentro de una situación de riesgo, no sin algunos matices importantes ${ }^{26}$. La presencia del elemento delictivo por sí solo no dará lugar a la declaración de riesgo, simplemente podría ser tenido en cuenta como un factor más, que en ausencia de otros indicadores no tendrá el suficiente peso para la intervención ${ }^{27}$. La solución alcanzada desde las legislaciones autonómicas para incluir a este colectivo fue la incorporación de una novedosa situación de desprotección: menores en dificultad social ${ }^{28}$. En efecto, con alcance y nomenclatura

${ }^{24}$ Para la comprensión de ambos modos de proceder en la declaración de la situación de riesgo revisar LEIVA RODRÍGUEZ, B. \& GARCÍA GARNICA, M.C. 2016, "Análisis de las instituciones del sistema de protección de menores", El genio Maligno, n 19: pp. 104-105.

${ }^{25}$ Cabe destacar la detallada enumeración de los supuestos que dan origen a declarar la situación de riesgo esgrimida por la Ley catalana 14/2010 de 27 de mayo, de los derechos y las oportunidades en la infancia y la adolescencia en su art. 102.

${ }^{26}$ Vid. BRAVO BARRIGA, S., 2016, "Protección jurídica e institucional del menor que comete delitos antes de los catorce años", Revista de Derecho Actual, vol. II, pp. 35-36; MONTERO HERNANZ, T. 2013, Los derechos de los menores infractores, Encuentro de Inspectores de Educación Valladolid: p. 29.

${ }^{27}$ Este planteamiento se debe a que la maquinaria del sistema de protección está orquestada para desenvolverse en un hábitat diseñado para atender a esquemas tradicionales que no corresponden con el del menor de 14 años delincuente ajeno a factores de desprotección. BERNUZ et al., "El tratamiento...", op. cit., p. 5.

${ }^{28}$ En palabras de De Palma Del Teso: "Los menores en dificultad social serían aquellos que por su situación de grave inadaptación pudieran encontrarse en riesgo de causarse perjuicios a sí mismos o a terceros". DE PALMA DEL TESO, A. 2011, "El derecho de los menores a recibir protección: el papel de la familia y de las administraciones públicas. La actuación de las administraciones públicas en situaciones 
diversa según la comunidad, prácticamente la totalidad de las leyes autonómicas, han implementado esta fórmula para englobarlo dentro de su competencia ${ }^{29}$.

Así por ejemplo, la comunidad de Andalucía a través de su Ley 1/1998 recoge en el art. 40 el concepto y las actuaciones de los menores en conflicto exponiendo lo siguiente:

"1. Se considerarán menores en conflicto social a los efectos de la presente Ley, aquellos que por situación de grave inadaptación pudiesen encontrarse en riesgo de causar perjuicios a sí mismo o a otros.

2. La actuación de la Administración Autonómica en esta materia habrá de tener como finalidad principal el desarrollo de acciones preventivas, así como la integración social de estos menores a través de un tratamiento educativo individualizado y preferentemente en su entorno sociocomunitario".

Igualmente, merece la pena detenerse en la definición dada por la Ley 12/2001, de 2 de julio, de la infancia y la adolescencia en Aragón (en adelante Ley 12/2001), por ser una disposición legal autonómica que incluye expresamente a los menores de 14 años que cometen ilícitos penales dentro del concepto de dificultad social. Así se refleja literalmente en su art. 78: "Se considerarán menores en conflicto social, a los efectos de la presente Ley, aquellos niños y adolescentes que pudiesen encontrarse en riesgo de causar perjuicios a sí mismos o a otros, así como aquéllos a los que les fuera aplicable la Ley Orgánica 5/2000, de 12 de enero, reguladora de la responsabilidad penal de los menores".

Una vez abordado el análisis de la situación de riesgo y de dificultad social, toca ahora el turno de exponer la realidad de la situación de desamparo y su vinculación con el tratamiento de menores que cometen ilícitos penales antes de los 14 años.

Para conocer la versión legal de la situación de desamparo debemos acudir al art.172 y siguientes del CC. En líneas generales estos artículos remarcan que la consecuencia de declarar en desamparo al menor está fundada en el incumplimiento, imposibilidad o falta de adecuación de los deberes de guarda por parte de los tutores legales ${ }^{30}$. A priori, habría que hacer encaje de bolillos para poder asimilar esta situación como correcta en la actuación con el grupo de menores protagonista. El principal argumento reside en la gravedad de la declaración de desamparo. No es óbice que la misma, inexorablemente determina la tutela del menor a la entidad pública y la retirada de la patria potestad a quien ostente los deberes de guarda sobre el menor.

Como hemos visto ya, la comisión de un delito no acarrea por si sola la situación de riesgo y ni mucho menos podrá alcanzar el grado exigido para declarar el desamparo del menor. Ambas situaciones están orientadas al contexto del menor pero cuando éste deviene totalmente normalizado no se llevará ninguna intervención por parte de los Servicios de Protección ${ }^{31}$.

de riesgo, dificultad social y desamparo de los menores", AFDUAM, no 15: p. 194.

29 SAINZ-CANTERO CAPARRÓS, B. 2014, "El modelo común para la intervención con menores en riesgo y desamparo propuesto por el Anteproyecto de Ley de Protección de la Infancia”, Revista de Derecho Civil, vol. 1, nº 4: p. 127.

${ }^{30}$ Acerca de la situación de desamparo ver LEIVA RODRÍGUEZ, B. \& GARCÍA GARNICA, M.C. 2016, “Análisis...", op. cit., p.106. Conviene también revisar la materia a nivel autonómico andaluz disponible en el art.23 Ley $1 / 1998$.

${ }^{31}$ BRAVO BARRIGA, S., 2016, “Protección...”, op. cit., p. 41. 
En otro orden de cosas, la ambigüedad reinante en la terminología empleada en muchas de las fases del discurso presentado en el articulado de la LO 1/1996 puede propiciar equívocos de cierta entidad incluso para los más duchos en la materia. En razón a este planteamiento decidimos incluir en este epígrafe unas pinceladas aclaratorias sobre la imposibilidad de maridar la intervención dada a los menores de catorce años que cometen un ilícito penal con la previsión recogida en el art.25 LO 8/2015. El referido artículo se expresa en los siguientes términos <<estarán destinados al acogimiento residencial de menores que estén en situación de guarda o tutela de la Entidad Pública, diagnosticados con problemas de conducta, que presenten conductas disruptivas o disociales recurrentes, transgresoras de las normas sociales y los derechos de terceros, cuando además así esté justificado por sus necesidades de protección y determinado por una valoración psicosocial especializada >. Bajo el paraguas de las palabras "problemas de conducta" podrían cobijarse algunas acepciones como la comisión de ilícitos penales. No obstante, la lectura del art. 25 nos da una pista sólida de que este internamiento no está relacionado con esa posibilidad, al poner como requisito la necesidad de estar bajo la tutela de la entidad pública. Ahondando un poco más en el contexto apreciamos que la terminología empleada obedece más al campo de la psicología y de la salud mental ${ }^{32}$. Estamos pues frente a menores que pueden o no haber cometido delitos pero que en ningún caso debe obviarse que el internamiento lleva aparejado unos problemas graves de conducta ${ }^{33}$.

\section{Experiencias concretas de varias provincias españolas ${ }^{34}$.}

La heterogeneidad marcada por la distinta disponibilidad de medios materiales, humanos y económicos hace que la estrategia de afrontamiento con la problemática de los delincuentes menores de 14 años tenga variopintas acepciones según la $\mathrm{C}$. A. de que se trate y más en particular, de la provincia en cuestión.

Desde esta perspectiva se hace interesante traer a colación a este artículo algunos de los programas más destacados a nivel nacional y a nivel de Andalucía, diseñados a tal efecto. En los siguientes párrafos se mostrará una selección de éstos, con el fin de poder establecer comparaciones y extraer conclusiones a nivel general de los diferentes estilos empleados en esta muestra ${ }^{35}$.

\footnotetext{
32 Jiménez Díaz se refirió al perfil de menores susceptibles de este internamiento de la siguiente forma: "Su situación psicológica y social demanda soluciones diferentes a las que ofrecen los centros de protección ordinarios o sus familias y requieren de un ingreso en centros especializados, previo informe sobre su situación social y sobre su estado psíquico". JIMÉNEZ DÍAZ, M. J. 2015, "Algunas reflexiones sobre la responsabilidad penal de los menores", Revista Electrónica de Ciencia Penal y Criminología, vol. 17-19: p. 11. [En línea] http://criminet.ugr.es/recpc/17/recpc1719.pdf.

${ }^{33}$ Para conocer los principales diagnósticos que conducen al internamiento en estos centros revisar; Síndic de Greuges de la comunitat valenciana, 2018, "Centros específicos de menores con problemas de conducta", pp. 9-10. [En línea] http://www.elsindic.com/wp-content/uploads/2018/05/SINDIC-librocentro-menorescon-problemas-de-conducta-CASTELLA_27feb.pdf

${ }^{34}$ Agradecemos desde estas líneas la colaboración de los diferentes miembros de estas entidades que participaron de manera activa en el conocimiento sobre su actividad.

${ }^{35}$ La selección presentada dista mucho de aglutinar todas las propuestas diseñadas a nivel nacional. Esta lista responde a criterios de accesibilidad y visibilidad de los programas. La diversa terminología empleada para la nomenclatura de los menores delincuentes de 14 años hace de la investigación una tarea de una extensión tanto temporal como cualitativa que escapa a las pretensiones de este trabajo.
} 


\section{$\underline{\text { A nivel nacional }}$}

\section{Zaragoza: Instituto Aragonés de Servicios Sociales, Equipo de Tratamiento Educativo para menores de 14 años (EMCA) ${ }^{36}$.}

A la hora de hablar del tratamiento de menores de 14 años en conflicto con la ley penal es de recibo destacar a Zaragoza como pionera y a la vez referente de esta modalidad de intervención. La andadura del EMCA comenzó en 2003 poco después de la entrada en vigor de la LO 5/2000. La pronta creación de este equipo de tratamiento da una idea de la predisposición existente entre la Fiscalía de Menores de Zaragoza y el Instituto Aragonés de Servicios Sociales y Familia, encabezado por el Área de menores en Conflicto Social, de crear un equipo técnico preparado para trabajar expresamente con este grupo. En consecuencia, el EMCA quedó encuadrado orgánicamente dentro de las Instituciones de Protección pero funcionalmente dependiente de la Fiscalía de Menores.

La especificidad es la seña de identidad de los destinatarios de los servicios del EMCA, que atenderán a aquellos menores de 14 años autores de hechos calificados como delictivos por las leyes penales que además, bajo el criterio de la fiscalía de menores, su intervención exceda las actuaciones habituales circunscritas al ámbito puramente familiar o educativo ${ }^{37}$.

Los pilares básicos sobre los que se asienta la intervención son la situación familiar y personal del menor, el hecho infractor y la víctima. Estos dos últimos conceptos constituyen los principales elementos diferenciadores respecto de otros programas de corte mucho más genéricos ${ }^{38}$. Los principios inspiradores más destacados: 1 . Principio de oportunidad; 2. Principio de voluntariedad; 3. Principio de intervención en el entorno del joven; 4. Principio de reprobación social. 5. Reparación del daño y conciliación con la víctima; 6. Principio de proporcionalidad y adecuación de la medida a aplicar; 7. Principio de restitución a la sociedad.

El proceder del miembro asignado del EMCA conlleva varias fases: una inicial de acopio de información sobre las circunstancias del hecho y la presencia o no de reincidencia. Asimismo, se comprueba si hay contacto previo con los servicios de protección u otra entidad para no duplicar actuaciones. La segunda parte de esta fase está orientada en la entrevista con el menor y la familia, con el fin de confrontar los hechos y obtener información de la dinámica familiar. Igualmente, si es necesario se recabará información del entorno social, educativo o de cualquiera que pidiera aportar datos interesantes de la vida del menor.

\footnotetext{
${ }^{36}$ Para más información sobre EMCA vid. BRAVO BARRIGA, S., 2016, “Protección...”, op. cit., pp. 100-108.; BERNUZ et al., "El tratamiento...", op. cit., pp. 13-17; CABALLERO, M.B.; CAMPODARVE, P. \& CIPRÉS, J. de B., 2012, "Intervención educativa con los menores de 14 años que presentan conductas calificadas como faltas o delitos por la Ley Penal", RES Revista de Educación Social; web oficial Gobierno de Aragón

[En línea] http://www.aragon.es/DepartamentosOrganismosPublicos/OOAA/IASS/Inicio/AreasAc tividad/Infancia/ci.infancia_seccion_05_conflicto_social.detalleInaem\#section3

${ }^{37}$ La marca de especificidad tiene su origen en una disposición legal, concretamente el art. 78 la ley 12/2001 cuya literalidad incluye a este colectivo concreto como destinatario de estos servicios, hecho que no resulta común en las leyes autonómicas sobre Protección de menores. A pesar de la reseñada especificidad y con una clara voluntad pragmática, el EMCA amplió su rango de actuación a menores reincidentes donde la actuación el ambiente familiar no hubiera repercutido en una corrección de las conductas reprobadas.

${ }^{38}$ De esta opinión CABALLERO, M. B. et. al., “Intervención...”, op. cit., p. 3.
} 
La segunda fase comienza una vez se ha recogida la información. En este punto se realizará un plan educativo en función de los factores de protección y de riesgo presentes.

Finalmente, en la última fase se le aplicará al menor uno o varios programas de intervención, según el criterio del experto.

2. Principado de Asturias: Asociación Centro Trama, Programa de menores infractores sin responsabilidad.

La Asociación Centro Trama (ONG) cuenta con amplio recorrido en la intervención con menores y otros colectivos. El centro de Oviedo realizó su apertura en $1998^{39}$.

El programa de menores infractores sin responsabilidad está fundamentalmente diseñado para menores entre 10-14 años que hayan cometido alguna infracción que de haber sido mayores de 14 años hubiera acarreado respuesta de la administración de justicia. En adicción a la condición anterior, se debe detectar por parte de los Servicios Sociales alguna situación de riesgo en cualquiera de las áreas formativa, familiar o comunitaria.

Dentro de su intervención, el delito se configura como factor de riesgo más, que normalmente viene acompañado de otros factores de riesgo. Esta pauta de actuación viene determinada en parte porque consideran un caso atípico el del menor que comete un ilícito penal y no presenta ningún otro factor de riesgo.

La línea de la intervención viene sustentada en la prevención, apoyada en la intransigible voluntariedad del sujeto y en una estrecha colaboración con el entorno familiar del menor. Desde este prisma abordan problemáticas como abuso de sustancias, violencia escolar o violencia interfamiliar entre otras. Por otro lado, las intervenciones suelen ser de larga duración y se promueve la responsabilización del menor respecto al hecho delictivo cometido.

\section{$\underline{\text { A nivel autonómico }}$}

En el ámbito autonómico de Andalucía hay 5 provincias (exceptuando Sevilla, Málaga y Cádiz) que tienen programas similares porque todos dependen orgánicamente de la Delegación Territorial de Igualdad, Salud y Políticas Sociales (en adelante DT), y a través del Servicio de Prevención y Apoyo a la Familia (en adelante SPAF) conceden los contratos a las distintas entidades ${ }^{40}$.

\footnotetext{
${ }^{39}$ Más información en https://www.trama.org/asociacion

40 Más información en la web de la Junta de Andalucía [En línea] https://www.juntadeandalucia.es/organismos/igualdadypoliticassociales/areas/infanciafamilias/apoyofamilias/paginas/programas-preventivos.html

En las provincias que no están incluidas en la enumeración, la intervención corre a cargo de:

Córdoba, Asociación Encuentr@cuerdos, Programa Preventivo de Atención, Orientación e Intervención con Familias Menores en Situación de Conflicto o Dificultad Social. https://encuentraacuerdos.wordpress.com/programas/programa-preventivo-deatencion-orientacion-eintervencion-con-familias-con-menores-en-situacion-deconflicto-o-dificultad-social/

Jaén, La Liga de la Educación-Liga Giennense, Programa de Intervención Socioeducativa para Menores de 14 años (PISE). http://ligaeducacion.org/proyectos2/jaen/

Almería, Asociación Medialmer, Programa ARGOS.
} 
3. Granada: PRYSMA: Programa para la Atención, Prevención, Orientación e Intervención a Familias con Menores en Situación de Conflicto o Dificultad Social., Asociación IMERIS ${ }^{41}$.

El programa de intervención socioeducativa con menores de 12 a 14 años que han cometido alguna infracción penal y acorde a la LO 5/2000 son irresponsables penalmente, lleva ya más de una década de recorrido. En el año 2008, la iniciativa de trabajar de manera focalizada con este colectivo en la provincia de Granada surgió de la asociación IMERIS (Intervención con menores en Riesgo Social). Desde entonces, bajo la pertenencia a un proyecto global denominado PRYSMA, se ha desarrollado sin dependencia directa de justicia y protección (pero si en colaboración con ellos); respondiendo orgánicamente a la DT.

El expediente abierto es derivado por Fiscalía hasta los Servicios de Protección de Menores, que apoyándose en la información previa recabada y en la valoración de los Servicios Sociales comunitarios, estimarán adjudicarle la intervención al SPAF cuando el caso no responde al esquema tradicional de los Servicios de Protección. En el último paso, el referido SPAF encomienda a la Asociación IMERIS una respuesta más específica al entrar dentro de uno de los perfiles recogidos en este programa.

El equipo multidisciplinar encargado de la intervención con el menor tiene como principio básico la voluntariedad del menor y de la familia, siendo este un requisito ineludible para comenzar la actuación. La asignación del profesional se organiza en función de la zona del domicilio del menor, de la gravedad de los hechos cometidos y del tipo de comportamiento problemático que exhibe. En otro orden de cosas, el catálogo de medidas empleadas es muy diverso en cuanto su naturaleza y contenido, pudiendo ir desde la simple amonestación hasta una intervención integral prolongada en el tiempo cuando se detectan múltiples factores de riesgo. Un año después de terminar la intervención, IMERIS realiza un seguimiento para comprobar la posible reincidencia del menor.

4. Huelva: Asociación PONTE de Iniciativas Psicológicas con Adolescentes y Familias $^{42}$, Programa Guía de Intervención con Familias para la Prevención de conductas antisociales.

El programa está dentro del SPAF provincial de la Junta de Andalucía en Huelva. La fiscalía de menores de Huelva deriva a los menores de 14 años que delinquen al SPAF. Esta instancia realiza una función de filtrado y determina que casos son proclives a la inclusión en el Programa.

El equipo de profesionales tiene como pauta de actuación un protocolo general en el que trabajan con diferentes perfiles de menores, en un continuo donde los menores pueden entrar y salir en función de la duración de la intervención. La presencia de algún ilícito penal en el expediente del menor es tratado igual que otro factor de riesgo, como por ejemplo, el absentismo escolar.

La intervención con los menores está impregnada de un denotado carácter preventivo y

http://www.medialmer.org/spip.php?article $=1094$

${ }^{41}$ Acerca de la Asociación IMERIS y del programa PRYSMA consultar http://www.imeris.org/programaprysma/; BRAVO BARRIGA, S., 2016, “Protección...”, op. cit., pp. 94-100.

42 Acerca de PONTE [En línea] https://www.asociacionponte.com/tag/huelva/ Consultado el 20 de diciembre de 2019. 
tiene la misión de proporcionar un toque de atención a los participantes, con la determinación de cortar la participación en la actividad ilegal en aras de evitar una ulterior entrada en el sistema de justicia juvenil.

PONTE también incide en el trabajo con los padres y la intervención se realiza teniendo en cuenta el entorno familiar. El consentimiento de los padres y del menor es de suma importancia porque de lo contrario no se podrá acceder al programa.

\section{El tratamiento institucional de los menores que cometen delitos antes de los 14 años en Málaga ${ }^{43}$.}

\subsection{Antecedentes}

Antes de comenzar con el análisis de la intervención que se realiza con los menores infractores de 14 años en Málaga, debemos referenciar el precedente que supuso el trabajo realizado en 2006 por la investigadora Pérez Jiménez ${ }^{44}$.

La ventaja de tener este trabajo es la posibilidad de establecer una comparativa para poder dilucidar en qué grado ha evolucionado el tratamiento institucional de estos menores.

Los resultados aportados por la investigación de 2006 generaron las siguientes conclusiones:

- La Junta de Andalucía no realizaba ningún tratamiento especial con los menores de 14 que cometían una infracción penal en Málaga.

- El servicio de protección del menor no había formado ningún equipo de profesionales específico para el trabajo con este grupo.

- De los expedientes procedentes de fiscalía solamente aquellos que tenían una problemática familiar y social grave terminaban siendo tratados, generalmente por un Equipo de Tratamiento Familiar (en adelante ETF).

No debemos dejar de lado que desde la investigación arriba comentada hasta la desarrollada en este trabajo, hay trece años de diferencia además de profundas reformas en el Sistema de Protección.

\subsection{Recorrido vital de un menor de 14 años a través de las distintas instituciones cuando comete un delito en Málaga.}

En aras de promover la sencillez y comprensión de la exposición de la actuación llevada a cabo con los menores de 14 años que cometen ilícitos penales en la ciudad de Málaga, vamos a explicar detenidamente como sería el trayecto del menor desde que comete el delito hasta que se le aplica una intervención, y la labor desarrollada por cada una de las entidades e instituciones implicadas.

La actuación original se identifica con la intervención de las Fuerzas y Cuerpos de Seguridad del Estado ante la posible comisión de un delito por un menor.

\footnotetext{
${ }^{43}$ Queremos agradecer desde estas líneas a todos los entrevistados su completa disposición a colaborar y la extraordinaria fuente de información que supusieron para la materialización de este trabajo.

${ }^{44}$ El desarrollo de la investigación completa en BERNUZ et al., "El tratamiento...”, op. cit., pp. 16-17.
} 
Generalmente la policía nacional o local se encarga de la actuación mediante la identificación la edad del menor, comprobando efectivamente que es menor de 14 años. Al no superar la edad indicada la intervención será siempre de carácter protector administrativo; se dará cuenta a Fiscalía de menores de los hechos y las circunstancias conocidas, además de remitir todas las actuaciones. La intervención acabaría con la conducción y traslado del menor hasta entregarlo a quienes ejerzan la patria potestad, la tutela, la guardia de hecho, o entidad pública de protección de menores ${ }^{45}$.

Una vez la fiscalía tiene conocimiento de la intervención debe proceder al envío del expediente al Sistema de Protección de Menores $^{46}$, en particular, derivará directamente, a la DT, integrada en la Junta de Andalucía.

La DT actúa como un canalizador del flujo de expedientes de menores provenientes de fiscalía y de otros medios ${ }^{47}$. Numerosos son los inconvenientes que dificultan la tarea como por ejemplo la falta de tiempo o de información. Su actuación se rige por el empleo de la herramienta Valórame, instrumento para la valoración de la gravedad de las situaciones de riesgo, desprotección y desamparo de la infancia en Andalucía ${ }^{48}$. La aplicación de Valórame permite hacer una evaluación del riesgo, dividiéndose en función de la intensidad del mismo en seis categorías que van desde la inexistencia de riesgo hasta la presencia de un riesgo grave unido a desamparo ${ }^{49}$.

La comisión de un acto ilícito cuenta como una llamada de atención para los servicios de protección pero no como factor de riesgo, así que en los casos que no se aprecian otros factores de riesgo la referida institución puede proceder al archivo del expediente. Ante la sospecha o falta de información se delegará a los Servicios Sociales Comunitarios dependientes del Ayuntamiento de Málaga, que indagarán acerca del caso puntual, llegando incluso a hacerse cargo cuando la intensidad de riesgo sea moderada.

En determinadas ocasiones la derivación del expediente del menor tendrá como

45 Sobre cómo debe ser la intervención policial con los menores de 14 años véase http://www.sipepol.es/wp-content/uploads/2017/05/1234-PROTOCOLOACTUACION-POLICIALCON-MENORES.pdf

${ }^{46}$ La Fiscalía de Menores sustenta sus actuaciones en el contenido del art.3 de la LO 5/2000 y a su vez debe tener muy presente lo recogido en el art.40 de la Ley 1/1998. A modo aclaratorio sobre la actuación del Fiscal se incluyen en el enlace inferior la circular 1/2000, de 18 de diciembre, relativa a los criterios de aplicación de la LO 5/2000. [En línea]

https://www.fiscal.es/fiscal/PA_WebApp_SGNTJ_NFIS/descarga/CI012000.pdf?idFile=18748173-3639468e-9595-1d4c1b7ba6d7

Por consiguiente, de la lectura de estos documentos se desprende que la Fiscalía no tiene obligación de profundizar en la investigación, limitándose a transmitir el expediente con toda la información obtenida acerca del menor y del hecho.

${ }^{47}$ La DT se erige como centro neurálgico del Sistema de Protección. Hasta aquí llegan expedientes por distintas vías y se derivan a diferentes recursos según las necesidades del menor. Por ejemplo, si se detecta la presencia en el menor de problemas de salud mental podrá derivarse a la USMI o al Instituto Psicopedagógico Dulce Nombre de María.

48 Acerca de Valórame [En línea] https://www.observatoriodelainfancia.es/oia/esp/valorame.aspx Consultado el 5 de enero de 2019.

Formulario Valórame. [En línea]

https://www.observatoriodelainfancia.es/oia/img/valorame/hoja_resumen_valora me.pdf Consultado el 5 de enero de 2019.

${ }^{49}$ Acerca de las categorías de riesgo consultar [En línea]

https://www.observatoriodelainfancia.es/oia/img/valorame/guia_rapida_valorame. pdf Consultado el 17 de febrero de 2019. 
destinatario a un servicio especializado dentro de los servicios sociales comunitarios denominado Equipo de Tratamiento Familiar (ETF). Los ETF desempeñan una intervención más destinada a una problemática familiar y social de carácter grave; con una especial atención a un enfoque centrado en prevención y detención del maltrato. Para los ETF la infracción en si no es el objetivo así que solo actuaran si el menor responde también a la reseñada disfuncionalidad familiar ${ }^{50}$. Al hilo de esta posible intervención del ETF, hay que destacar que debe contar con el consentimiento de los padres y del menor ${ }^{51}$. La negativa en la mayoría de la casuística no acarreara más que una anotación en el expediente dejando constancia de la oposición a la participación ${ }^{52}$.

La realidad a día de hoy demuestra que Málaga está lejos de tener un equipo técnico diseñado expresamente para afrontar la intervención con el grupo protagonista de este trabajo $^{53}$. Más preocupante aun si cabe es falta de preocupación por incluir como destinatarios de un programa preventivo a este colectivo. En este sentido, no se entiende como otras provincias andaluzas tengan al menos, programas dirigidos a los menores de 14 años que han cometido una infracción penal ${ }^{54}$, y Málaga siga carente de esta modalidad de intervención.

Como cierre a este epígrafe podemos aseverar que los resultados obtenidos por la investigación precedente se han reiterado en esta investigación.

\section{Conclusiones.}

La estructura del trabajo se encuentra divida en tres partes bien diferenciadas relacionadas intrínsecamente con las hipótesis primigenias, y con el ánimo de exponer con mayor claridad las conclusiones obtenidas, se respetará la misma disposición organizativa en este epígrafe.

En primer lugar, el ámbito legal nacional en materia de Protección de la Infancia maneja un esquema basado en la prevención e intervención del maltrato y/o del

\footnotetext{
${ }^{50}$ Sobre el funcionamiento de los ETFs conviene consultar el Decreto 494/2015 de 9 de febrero de 2015 por el que se regula y gestiona el Programa de Tratamiento a Familias con Menores en situación de riesgo o desprotección [En línea:] https://www.juntadeandalucia.es/boja/2015/237/1; Decreto 210/2018, de 20 de noviembre, por el que se regula el procedimiento de actuación ante situaciones de riesgo y desamparo de la infancia y adolescencia en Andalucía (SIMIA). [En línea] https://www.juntadeandalucia.es/boja/2018/227/4 Consultado el 15 de febrero de 2019

51 Según las explicaciones de los distintos operadores la negativa del menor ofrece menos problemas porque es normal que reaccionen oponiéndose a la intervención. Por regla general, los padres son más conscientes de la situación del menor y cuando se les insta a colaborar, participan por el bien del menor.

52 Podría activarse el protocolo de desamparo si la negativa de los padres repercute en el interés del menor. De llegar a completarse la Junta asumiría la tutela, dejando sin efecto la patria potestad de los tutores legales, aunque debido a la excepcional gravedad de esta medida, rara vez se aplica.

${ }^{53}$ A colación a esta afirmación conviene señalar que la Asociación ALME, adjudicataria de la ejecución de las medidas de reforma de los menores de14 a 17 años, informa en su web oficial de: "La elaboración de un Proyecto para la implementación de un Programa preventivo con menores de 14 años en situación de riesgo social". [En línea] http://www.asociacionalme.org/otrosprogramas.html

Desconocemos el por qué no cristalizó el proyecto o si simplemente se quedó en una propuesta sin desarrollar, pero lo que si podemos afirmar es que no se materializó por parte de ALME ni de otra asociación ningún programa que tuviera dentro de sus destinatarios a los menores de 14 años que cometen ilícitos penales.

${ }^{54} \mathrm{Si}$ bien es cierto que no son programas exclusivos y abarcan otros perfiles diferentes. En adicción, los tratamientos dados no centran su atención en la comisión de infracción penal.
} 
abandono. Alrededor de esta premisa han ido introduciéndose reformas y modificaciones con en el fin de amoldarse a las exigencias sociales del momento. Como hemos comprobado, la LO1/1996 carece de alguna referencia expresa a categorizar como riesgo la infracción penal de los menores de 14 años. Tampoco contiene en su articulado la mención a riesgo por dificultad social atesorada en las leyes de las CC.AA.

Sin olvidar el carácter supletorio de la LO 1/1996 respecto de las leyes comunitarias en materia de protección de menores, se aprecia una falta de impulso desde el ámbito nacional para solventar esta deficiencia, a pesar de la obligación expresa emanada desde el art.3 de la LO 5/2000. La constancia en la LO 1/1996, al menos proporcionaría un marco general de referencia a las leyes autonómicas, convirtiéndose en un reclamo para que éstas le concedieran la importancia debida en su actividad legisladora.

La incomparecencia a nivel nacional deja fuera de su radio de acción al grupo de menores que comete ilícito penal antes de los 14 años, corroborando nuestra hipótesis inicial. El vacío originado alimenta sobremanera el debate social acerca de cuál es el método más conveniente para responder ante este colectivo, y vista la inhabilidad manifiesta del sistema actual de protección, no es de extrañar que la reducción de la edad mínima para exigir responsabilidad penal gane cada día más adeptos.

Entre tanto una legislación diseñada en función del binomio desprotección/protección de los menores, permanece indiferente ante un fenómeno sensiblemente diferente al modelo estándar de menor con el que usualmente trabaja. En consecuencia, la declaración de intenciones de cimentar una intervención sólida que evitara el avance hacia siguiente paso en la carrera delictiva de estos menores, carece de un cuerpo legislativo robusto que respalde esta afirmación.

El colapso de un idealizado sistema de protección a caballo entre la impunidad y la justicia juvenil hace zozobrar una parte fundamental de la política criminal juvenil española. Planteados los síntomas, apremia resolver cómo abordar el problema, bien asumiendo el control por medio de la bajada de la edad mínima de responsabilidad penal o bien dotando al sistema de protección de elementos eficaces para la intervención de estos menores.

En segundo lugar, en lo atinente a la actuación con este grupo de menores se arrastran los males de un cuerpo legislativo desconectado de esta función. Sin embargo, gracias a la labor del legislador autonómico se ha podido introducir en la intervención, eso sí con calzador, a los menores de 14 años que cometen ilícitos penales.

La terna de programas de intervención aquí presentados, se encuentran alojados dentro de la cobertura ofrecida por el concepto de menor en dificultad social. Desde punto de partida, se intenta buscar acomodo a estos menores junto a otros perfiles alejados de la delincuencia. Profusa es la literatura criminológica versada sobre la delincuencia juvenil que apunta decididamente como una de las principales causas de la misma a la presencia de factores de índole socioambiental. Sumada a esta apreciación, la experiencia de los profesionales que trabajan con menores suele reafirmar los resultados positivos de una intervención integral englobando dichos factores.

Los enumerados argumentos forman un excelente caldo de cultivo para abarcar la intervención de los menores que cometen delitos antes de los 14 años; y muy 
posiblemente, tengan un éxito elevado cuando la entidad del delito sea leve. No obstante, el tratamiento no especificado sin una especial atención a la idiosincrasia delictual comporta capitales consecuencias.

La primera, ya mencionada, recae en la inacción de los profesionales cuando no hay otras causas de desprotección, con la ya sabida incidencia negativa en la persona del menor. La segunda repercute indirectamente en el sistema de justicia juvenil, al no recibir la atención conveniente los menores involucrados en delitos de mayor lesividad o incluso de extrema gravedad, éstos muy probablemente pasarán a engrosar sus estadísticas de delincuencia juvenil. Resulta cuanto menos contraproducente que este perfil "comparta" su intervención con otros perfiles como el de un absentista escolar. $\mathrm{Y}$ es que, el perjuicio tornaría en una doble dirección al verse afectados adversamente sendos perfiles.

Rehuir el hecho delictivo en el diseño de los programas obliga a pagar una elevada factura a los menores en el momento de llegar a los 14 años. Resulta difícil comprender por qué no se evita tan funesto desenlace poseyendo las bases para tener en consideración el factor delictual. Parapetarse detrás de un errado enfoque legislativo de desprotección no es más que una contumaz actitud, en la medida que la propia ley presenta los argumentos para tratar el delito como una verdadera situación de riesgo por sí misma.

Riesgo intrínseco ligado a que llegada la edad estimada, la sola comisión del delito puede acarrear en el peor de los casos el internamiento en un centro de menores, si el delito es calificado como muy grave. A nuestro juicio, no resulta comprensible no actuar para eludir esa plausible posibilidad por más remota que pueda parecer. En cambio, tan poco halagüeño porvenir se asemeja ostensiblemente a una situación de desprotección del menor, pudiéndose reaccionar en el presente en pos de una prevención efectiva redundante en el futuro.

Ahora bien, cargar las tintas sobre los distintos profesionales que trabajan con estos menores no deviene admisible en tanto en cuanto sus recursos económicos, personales y de todo tipo flaquean de manera alarmante. Especialmente acuciante es el desbordamiento de los servicios sociales primarios que deben atender una ingente cantidad de expedientes y temáticas. No en vano, la excesiva carga de trabajo es un denominador común en prácticamente todas las instituciones y entidades.

En referencia a la enorme diversidad de actuaciones, convendría estipular un protocolo de actuación a nivel nacional para intervenir con los menores que delinquen antes de los 14 años, en el cual los equipos de tratamiento especializados ocuparan un papel preponderante. Una eficiente canalización del paso de los menores por las distintas estancias institucionales contribuiría satisfactoriamente a simplificar el proceso. Sin ir más lejos, sería recomendable mejorar la calidad de la investigación inicial porque de ella va a suponer la fundamentación de gran parte de la intervención ulterior.

Al escapar de la competencia de la LO 5/2000, las directrices al estamento policial y a la Fiscalía se encuentran sumamente limitadas impidiendo una mayor profundización en la investigación de estos casos. En no pocas ocasiones la información recopilada es escasa y a la llegada del expediente a Protección de Menores se desconocen muchos detalles importantes para derivar al menor al servicio correcto. Una práctica habitual es la derivación a los servicios sociales comunitarios para que realicen ellos la 
investigación, pero recordemos que poco podrán indagar sobre el suceso delictivo en sí.

Si el protocolo nacional debiera contener al menos la implementación de los equipos técnicos especializados y el fomento de la investigación primigenia, en el seno de las CCAA, correspondería optimizar los recursos disponibles en aras de una maximización de los beneficios personales y económicos. No olvidemos que es competencia del gobierno de las CC.AA dotar de una infraestructura equipada y preparada para acometer la intervención con este colectivo.

Incluso sería muy productivo que cada C.A. asumiera el protocolo nacional como un esqueleto vertebrador necesario pero adaptándolo a las peculiaridades de cada región, y siendo más estrictos a cada provincia. Claramente, las necesidades de cada provincia van a diferir dependiendo de factores tan dispares como tamaño de la población juvenil o situación geográfica. Como ejemplo vale la pena citar a Andalucía donde aun siendo parte de la misma C.A. los menores delincuentes no tienen el mismo perfil en Cádiz que en Jaén. Está minuciosidad en la estrategia de intervención permitiría un mayor éxito con los menores a la par que generaría una mejor percepción social de un malogrado Sistema de Protección.

En atención al contexto andaluz, la Junta de Andalucía no ha acompasado la remodelación del Sistema de Protección de menores a las exigencias y necesidades que se venían reclamando ya desde hace varios años. El resultado deviene en un sistema arcaico incapaz de resolver la problemática delictual desde un enfoque más específico, en convivencia con los factores de desprotección pero que no permanece inerme ante la comisión de infracciones penales por parte de los menores referidos.

Desde la Junta se ha potenciado la vinculación con entidades donde se impartían programas que incluían a estos menores como receptores, siempre fundamentando tal intervención desde el art.40 de la LO 1/1998. Curiosamente, las tres provincias con más población y mayores índices de delincuencia juvenil se han quedado fuera de esta iniciativa contradiciendo así nuestra segunda hipótesis. Si bien es cierto que estos programas se encuentran lejos de ser específicos para menores de 14 años infractores penales, no lo es menos que suponen un avance con respecto a la inobservancia de los mismos presente en Málaga, Sevilla y Cádiz.

La razón de esta decisión es víctima de un contrasentido cuanto menos llamativo y de difícil explicación. La argumentación quizá más acertada al respecto deviene de una decisión política de no incluir a estas provincias por el supuesto elevado coste que supondría. En cualquier caso, la única certeza es la imperiosa necesidad de como mínimo articular programas similares en los territorios reseñados.

Por último, procede realizar algunos apuntes relevantes surgidos a raíz de la investigación en Málaga. Málaga sigue misteriosamente huérfana de un tratamiento especial para los menores que han cometido una infracción penal. Como ya pusiera de relieve la investigación anterior y confirmando nuestra tercera hipótesis, el criterio de la Junta de Andalucía en esta ciudad, consiste en atender esta problemática de manera general, obviando la perspectiva delictiva del fenómeno. Sin duda, el dato más destacable, es que el paso del tiempo no ha venido aparejado de una remodelación de la estrategia y un mejor uso de los recursos. La falta de adaptación a la LO 5/2000 o el desconocimiento de esta realidad difícilmente pueden ser argüidas como razones convincentes después de tanto tiempo. Y es que la falta de equipo específico no solo 
repercute en el tratamiento de los menores sino también en el correcto funcionamiento de las instituciones.

El primer caballo de batalla vendría de la mano de no cargar con la investigación ni la intervención a los servicios sociales comunitarios. La saturación a la que se ven expuestos repercute negativamente en una correcta evaluación del menor. Si se quiere seguir manteniendo a estos profesionales en esta labor, necesitan un aumento de personal impostergable.

En no mucho mejor situación se encuentran los ETF, que con una respuesta más elaborada tampoco pueden incidir todo lo que quisieran en la intervención. Además utilizan parámetros muy rígidos basados en instrumentos típicos de protección que impiden profundizar en otros ámbitos de la intervención. Por desgracia, su participación se ve abocada a un quiero y no puedo inadmisible.

La responsabilidad de redistribución de expedientes recibidos de Fiscalía, vulgarmente denominados LO, en alusión a la LO 5/2000, recae enteramente en discrecionalidad de la DT. A nuestro modo de ver, esta institución sería la gran beneficiada de la creación de un equipo específico, porque la labor de filtrado para ver a qué servicio o entidad hay que derivar el expediente, quedaría suspendida. Así las cosas, en el momento que llegará un expediente de Fiscalía nada más habría que derivar al equipo específico para que determinara la actuación con el menor.

Como colofón a este apartado de las conclusiones, merece la pena exponer el sentir de los protagonistas malacitanos. Existe un núcleo muy minoritario de ciertas voces resignadas que ante la incertidumbre de ese deseo, abogan por que la justicia juvenil asimile a estos menores para no sentirse impotentes y anhelar que cumplan los 14 años para recibir una intervención adecuada. En contraste, la opinión generalizada de los distintos operadores en Málaga a la que nos adherimos, apuesta por no reducir la edad penal y seguir actuando desde el sistema de protección por sus mejores prestaciones para el tratamiento del menor de 14 años. En este planteamiento destacan la necesidad de la formación de un equipo específico que descargue de trabajo a todos los involucrados y sobre todo que esté capacitado para dar una respuesta a medida a los menores.

\section{Bibliografía.}

-ALEMÁN BRACHO, C., 2014, "Políticas públicas y marco de protección jurídica del menor en España", UNED. Revista Derecho Político, n 90, pp. 97-134.

-BERNUZ, M. J.; FERNÁNDEZ, E.; PÉREZ, F., 2006, "El tratamiento institucional de los menores que cometen delitos antes de los 14 años", Revista Española de Investigación criminológica, $\mathrm{n}^{\circ}$ 4, artículo 5, pp. 1-25.

-BERNUZ, M. J.; FERNÁNDEZ, E.; PÉREZ, F., mayo de 2007, “Menores de 14 años que cometen delitos”, Boletín criminológico sección de Málaga IAIC, no 97 pp.1-4. [En línea] http://www.boletincriminologico.uma.es/boletines/97.pdf 
-BENAVENTE MOREDA, P., 2011, "Riesgo, Desamparo y Menores .Actuación de la Administración e intereses en juego”, AFDUAM, vol.15, p. 15-62.

-BRAVO BARRIGA, S., 2016, "Protección jurídica e institucional del menor que comete delitos antes de los catorce años", Revista de Derecho Actual, vol. II, pp. 1135.

-CABALLERO, M.B.; CAMPODARVE, P. \& CIPRÉS, J. de B., 2012, “Intervención educativa con los menores de 14 años que presentan conductas calificadas como faltas o delitos por la Ley Penal", RES Revista de Educación Social, nº 15, pp. 1-12.

-CABEZAS SALMERÓN, J., 2011, "Superación del modelo anterior de Justicia Juvenil (tutelar) por el actual modelo de responsabilidad (de responsabilidad) ¿Se lo ha creído alguien?", Revista Crítica Penal y Poder, no 1, pp. 158-173. [En línea] revistes.ub.edu/index.php/CriticaPenalPoder/article/download/1991/2087

-CABEZAS SALMERÓN, J., 2012, "Protegernos de los jóvenes", Revista Crítica Penal y Poder, $\mathrm{n}^{\mathrm{o}}$ 2, marzo, pp. 189-200. [En línea] http://revistes.ub.edu/index.php/CriticaPenalPoder/article/view/2951/3214

-CARRASCO, N.; GARCÍA, J. \& ZALDÍVAR, F., 2014, "Estimación y caracterización de los antecedentes de protección de los menores infractores", Anuario de Psicología Jurídica, vol. 24, no 1, pp. 31-35. [En línea] https://www.redalyc.org/articulo.oa?id=315031876004

-DE PALMA DEL TESO, A. 2011, "El derecho de los menores a recibir protección: el papel de la familia y de las administraciones públicas. La actuación de las administraciones públicas en situaciones de riesgo, dificultad social y desamparo de los menores", AFDUAM, no 15: p. 185-215.

-GARCÍA PÉREZ, O.; 1999, "Los actuales principios del derecho penal juvenil: un análisis crítico", Revista de derecho penal y criminología, n 3, 33-76.

-JIMÉNEZ DÍAZ, M. J., 2015, “Algunas reflexiones sobre la responsabilidad penal de los menores”, Revista Electrónica de Ciencia Penal y Criminología, vol. 17-19, pp. 136. [En línea] http://criminet.ugr.es/recpc/17/recpc17-19.pdf

-LEIVA RODRÍGUEZ, B.; GARCÍA GARNICA, M. C., 2016, "Análisis de las instituciones del sistema de protección de menores”, El genio Maligno, n 19, pp. 96124.

-LUZÓN GARCÍA, A.; DOMÍNGUEZ ALONSO, J., 2014, "El menor infractor que comete su primer delito", Revista sobre la infancia y la adolescencia, ${ }^{\circ}$ 7: pp. 40-57.

-MONTERO HERNANZ, T., 2013, Los derechos de los menores infractores, Encuentro de Inspectores de Educación Valladolid, pp. 1-85. 
-MORENO-TORRES SÁNCHEZ, J., 2015, "Modificación del Sistema de Protección a la Infancia y a la Adolescencia, Save the Children, pp. 1-70. Pacheco Gallardo, M., 2007, “Criminología Juvenil", Noticias Jurídicas, fecha de consulta 28 enero 2019, en http://noticias.juridicas.com/conocimiento/articulosdoctrinales/4333-criminologiajuvenil-/.

-PACHECO GALLARDO, M., 2007, "Criminología Juvenil", Noticias Jurídicas, fecha de consulta 28 enero 2019, en http://noticias.juridicas.com/conocimiento/articulosdoctrinales/4333-criminologiajuvenil-/

-SÁEZ TEJERINA, M. L., 2004, "La protección de la infancia en España y en las comunidades autónomas". Cuartas jornadas sobre Infancia, Redes de formación e investigación para la promoción de los derechos de la Infancia, jornada 5, pp. 1-19.

-SAINZ-CANTERO CAPARRÓS, B., 2014, “El modelo común para la intervención con menores en riesgo y desamparo propuesto por el Anteproyecto de Ley de Protección de la Infancia”, Revista de Derecho Civil, vol. 1, nº 4, pp. 107-153.

-SINDIC DE GREUGES DE LA COMUNITAT VALENCIANA, 2018, "Centros específicos de menores con problemas de conducta", pp.9-10. [En línea] http://www.elsindic.com/wpcontent/uploads/2018/05/SINDIC-libro-centro-menorescon-problemas-de-conductaCASTELLA_27feb.pdf

-SOTO NAVARRO, S., 2005, "La influencia de los medios en la percepción social de la delincuencia”, Revista Electrónica de Ciencia Penal y Criminología, nº 07-09, pp. 1-46. [En línea] http://criminet.ugr.es/recpc/07/recpc07-09.pdf 